\title{
ANALISIS KEPUASAN MASYARAKAT DALAM PENGURUSAN SURAT IJIN USAHA PERDAGANGAN AGRIBISNIS MELALUI BADAN PELAYANAN PERIJINAN TERPADU SATU PINTU DAN PENANAMAN MODAL KOTA DENPASAR
}

\author{
Analysis of Public Satisfaction in Agribusiness Trade Agreement Management \\ through Integrated Licensing Service Agency One Door \\ and Investment City of Denpasar
}

\author{
Ni Putu Vivi Febryana, Ketut Budi Susrusa,_I Made Sudarma
}

Program Studi Magister Agribisnis, Fakultas Pertanian, Universitas Udayana, Bali, Indonesia

E-mail: vivifebryana@yahoo.co.id

\begin{abstract}
The main function of the government is to serve the community. Increasing public satisfaction is one of the efforts to improve the quality of public services. Trading business license services for agricultural investment activities (agribusiness) is one of the licensing services provided by One Stop Service Permit and Investment Board (BPPTSP and PM) in Denpasar City. This study aims to analyze the Public Satisfaction in the management of Agribusiness license in BPPTSP and PM of Denpasar City. Analysis method in this study using Partial Least Square (PLS) with the help of Smart PLS Version 3 program that measures the satisfaction of the community in managing the agribusiness license based on three variables namely; service standards, bureaucratic performance, and service quality. The results of this study indicate that the three variables are very positive effect on the satisfaction of the community in managing the business license Agribusiness in BPPTSP and PM Denpasar. Improvement of service standards, bureaucratic performance and service quality in the management of trading business license in BPPTSP and PM of Denpasar City will increase the satisfaction of the public in the business license arrangement, thus the community is increasingly interested to manage the legality of their business independently. Increasing the management of trading business permit, especially in the field of Agribusiness will reduce the number of illegal companies in Denpasar City, so that Agribusiness companies in Denpasar City can operate in the market legally and safely, and people can buy agribusiness's products safely without fear of harmful content on the product.
\end{abstract}

Keywords: Service standards, bureaucratic service performance, service quality, community satisfaction, BPPTSP and PM of Denpasar City.

\begin{abstract}
ABSTRAK
Fungsi utama pemerintah adalah melayani masyarakat. Meningkatnya kepuasan masyarakat merupakan salah satu upaya untuk meningkatkan kualitas pelayanan publik. Layanan lisensi usaha perdagangan untuk kegiatan investasi pertanian (agribisnis) merupakan salah satu layanan perizinan yang diberikan oleh Badan Pertanahan dan Penanaman Modal (BPPTSP dan PM) di Kota Denpasar. Penelitian ini bertujuan untuk menganalisis Kepuasan Publik dalam pengelolaan izin Agribisnis di BPPTSP dan PM Kota Denpasar. Metode analisis dalam penelitian ini menggunakan Partial Least Square (PLS) dengan bantuan program Smart PLS Version 3 yang mengukur kepuasan masyarakat dalam mengelola izin agribisnis berdasarkan tiga variabel yaitu; standar pelayanan, kinerja birokrasi, dan kualitas pelayanan. Hasil penelitian ini menunjukkan bahwa ketiga variabel tersebut sangat berpengaruh positif terhadap kepuasan masyarakat dalam mengelola izin usaha Agribisnis di BPPTSP dan PM Denpasar. Peningkatan standar pelayanan, kinerja birokrasi dan kualitas layanan dalam pengelolaan izin usaha perdagangan di BPPTSP dan PM Kota Denpasar akan meningkatkan kepuasan masyarakat dalam pengaturan izin usaha, sehingga masyarakat semakin tertarik untuk mengelola legalitas usaha mereka. mandiri. Peningkatan pengelolaan izin usaha perdagangan, khususnya di bidang Agribisnis akan mengurangi jumlah perusahaan ilegal di Kota Denpasar, sehingga perusahaan Agribisnis di Kota Denpasar dapat beroperasi di pasar secara legal dan aman, dan masyarakat dapat membeli produk agribisnis dengan aman tanpa rasa takut. dari konten berbahaya pada produk.
\end{abstract}


Kata kunci: Standar pelayanan, kinerja pelayanan birokrasi, kualitas pelayanan, kepuasan masyarakat, BPPTSP dan PM Kota Denpasar.

\section{PENDAHULUAN}

\section{Latar Belakang}

Fungsi utama pemerintah adalah melayani masyarakat maka pemerintah perlu terus berupaya meningkatkan kualitas pelayanan, salah satu upayanya adalah meningkatkan kualitas pelayanan publik. Salah satu bentuk jenis layanan perijinan yang diselenggarakan oleh Pemerintah Kota Denpasar kepada masyarakat di Badan Pelayanan Perijinan Terpadu Satu Pintu dan Penanaman Modal (BPPTSP dan PM) Kota Denpasar adalah pelayanan Surat Ijin Usaha Perdagangan (SIUP) untuk kegiatan investasi yang berkaitan dengan usaha pertanian (agribisnis).

Penelitian ini menganalisis perilaku dan standar layanan yang mempengaruhi tingkat kepuasan masyarakat. Menurut Keputusan Menteri Pendayagunaan Aparatur Negara Nomor KEP/25/M/PAN/2/2004 tentang Pedoman Penyusunan Indeks Kepuasan Masyarakat Unit Pelayanan Instansi Pemerintah ada empat belas hal yang berkaitan dengan kepuasan masyarakat terhadap; pelayanan yang dilakukan oleh petugas pelayanan antara lain kejelasan petugas pelayanan, kedisiplinan petugas pelayanan, tanggung jawab petugas pelayanan, kemampuan petugas pelayanan, kecepatan pelayanan, keadilan mendapatkan pelayanan, kesopanan, dan keramahan petugas pelayanan, prosedur pelayanan, persyaratan pelayanan, kewajaran biaya pelayanan, kesesuaian biaya pelayanan, kepastian jadwal pelayanan, kenyamanan lingkungan, dan keamanan lingkungan.

\section{Rumusan Masalah}

Berdasarkan latar belakang di atas, dapat dirumuskan masalah sebagai berikut:

1. Bagaimana pengaruh standar layanan terhadap kepuasan masyarakat dalam mengurus SIUP Agribisnis pada BPPTSP dan PM di Kota Denpasar?

2. Bagaimana pengaruh kinerja birokrasi terhadap kepuasan masyarakat dalam mengurus SIUP Agribisnis pada BPPTSP dan PM di Kota Denpasar?

3. Bagaimana pengaruh kualitas pelayanan terhadap kepuasan masyarakat dalam mengurus SIUP Agribisnis pada BPPTSP dan PM di Kota Denpasar?

4. Bagaimana pengaruh standar layanan terhadap kinerja birokrasi dalam mengurus SIUP Agribisnis pada BPPTSP dan PM di Kota Denpasar?

5. Bagaimana pengaruh kinerja birokrasi terhadap kualitas pelayanan dalam mengurus SIUP Agribisnis pada BPPTSP dan PM di Kota Denpasar?

\section{Tujuan Penelitian}

Tujuan penelitian ini adalah sebagai berikut:

1. Mengetahui pengaruh standar layanan terhadap kepuasan masyarakat dalam pengurusan SIUP Agribisnis pada BPPTSP dan PM di Kota Denpasar.

2. Mengetahui pengaruh kinerja birokrasi terhadap kepuasan masyarakat dalam pengurusan SIUP Agribisnis pada BPPTSP dan PM di Kota Denpasar. 3.Mengetahui pengaruh kualitas pelayanan terhadap kepuasan masyarakat dalam pengurusan SIUP Agribisnis pada BPPTSP dan PM di Kota Denpasar.

3. Mengetahui pengaruh standar layanan terhadap kinerja birokrasi dalam pengurusan SIUP Agribisnis pada BPPTSP dan PM di Kota Denpasar.

4. Mengetahui kualitas pelayanan terhadap kinerja birokrasi dalam pengurusan SIUP Agribisnis pada BPPTSP dan PM di Kota Denpasar.

\section{KAJIAN PUSTAKA}

\section{Teori Pelayanan Publik}

Pelayanan publik sering dilihat sebagai representasi dari eksistensi birokrasi pemerintahan, karena hal itu bersentuhan langsung dengan tuntutan kebutuhan masyarakat. Filosofi dari pelayanan publik menempatkan rakyat sebagai subyek dalam penyelenggaraan pemerintahan (Rachmadi, 2008). Sebelum mengetahui arti kinerja pegawai publik, perlu diketahui terlebih dahulu mengenai organisasi publik. Organisasi publik diartikan sebagai organisasi yang dilakukan oleh pemerintah terhadap sejumlah manusia, yang memiliki setiap kegiatan yang menguntungkan dalam suatu kumpulan atau kesatuan, dan menawarkan kepuasan meskipun hasilnya tidak terikat pada suatu produk secara fisik (Sinambela, 2007).

\section{Teori Standar Layanan}

Setiap penyelenggaraan pelayanan harus memiliki standar pelayanan dan dipublikasikan sebagai jaminan adanya kepastian bagi penerima pelayanan. Standar pelayanan merupakan ukuran yang dibakukan dalam penyelenggaraan pelayanan publik yang wajib ditaati oleh pemberi dan atau penerima pelayanan. Menurut Wahyuni (2006) standar pelayanan publik berfungsi untuk memberikan arah bertindak bagi instansi penyedia pelayanan publik, di mana dengan ditetapkannya suatu standar atas pelayanan publik, maka dapat mempermudah instansi penyedia pelayanan untuk menentukan strategi dan prioritas. 


\section{Teori Birokrasi Pelayanan}

Karl Marx (dalam Thoha, 2005) menyatakan birokrasi adalah negara atau pemerintah itu sendiri. Lebih lanjut Marx mengemukakan bahwa birokrasi merupakan instrumen yang di pergunakan oleh kelas yang dominan untuk melaksanakan kekuasaan dominasinya atas kelas-kelas sosial lainnya. Paradigma ekonomi klasik menyatakan bahwa ada empat peran utama dari pemerintah: distribusi,stabilisasi,pertahanan dan kemananan serta pemenuhan sektor publik (Musgrave,1980).

\section{Teori Kualitas Pelayanan}

Kualitas merupakan suatu kondisi dinamis yang berpengaruh dengan produk, jasa, manusia, proses dan lingkungan yang memenuhi atau melebihi harapan (Tjiptono, 2001). Sehingga definisi kualitas pelayanan dapat diartikan sebagai upaya pemenuhan kebutuhan dan keinginan konsumen serta ketepatan penyampaiannya dalam mengimbangi harapan konsumen (Tjiptono, 2007). Kualitas pelayanan (service quality) dapat diketahui dengan cara membandingkan persepsi para konsumen atas pelayanan yang nyata-nyata mereka terima atau peroleh dengan pelayanan yang sesungguhnya mereka harapkan atau inginkan terhadap atribut-atribut pelayanan suatu perusahaan.

\section{Teori Kepuasan Konsumen}

Kepuasan adalah perasaan senang atau kecewa seseorang yang muncul setelah membandingkan antara persepsi atau kesan terhadap kinerja atau hasil suatu produk dan harapan-harapannya (Kotler, 2001). Kepuasan merupakan fungsi dari persepsi atau kesan atas kinerja dan harapan. Jika kinerja berada dibawah harapan maka pelanggan tidak puas. Jika kinerja memenuhi harapan maka pelanggan akan puas. Jika kinerja melebihi harapan maka pelanggan akan amat puas atau senang.Kunci untuk menghasikan kesetian pelanggan adalah memberikan nilai pelanggan yang tinggi.

\section{KERANGKA KONSEP PENELITIAN}

Adapun bentuk kerangka konsep yang ingin disampaikan melalui penelitian ini adalah sebagai berikut :

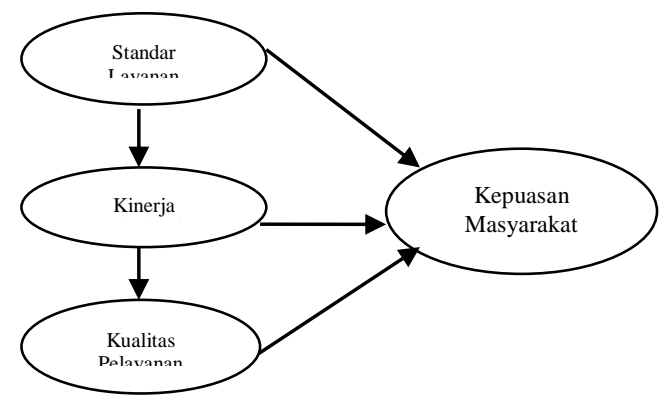

Gambar 1. Kerangka Konsep Penelitian

\section{METODE PENELITIAN}

\section{Lokasi dan Waktu Penelitian}

Penelitian terkait dengan pengurusan SIUP Agribisnis di BPPTSP dan PM Kota Denpasar yang berlokasi di Graha Sewaka Dharma Jalan Majapahit Lumintang Denpasar. Penelitian dilaksanakan dari bulan Juni s/d Nopember 2016.

\section{Sumber Data dan Sampel Penelitian}

Data yang digunakan dalam penelitian ini adalah data primer yang diperoleh secara langsung dari sumber asli. Data Primer yang diperlukan pada penelitian ini adalah data jumlah pemohon ijin yang memperpanjang maupun mengurus ijin usaha baru di bidang Agribisnis dari bulan Juni s/d Nopember 2016. Pengambilan sampel penelitian menggunakan teknik purposive sampling dan accidental sampling. Sampel yang diperoleh pada penelitian ini adalah sebanyak 70 orang.

\section{Metode Analisis Data}

Analisis ini dilakukan berdasarkan tujuan penelitian dengan menggunakan bantuan software Smart PLS, adapun model sem yang digunakan sebagai berikut:

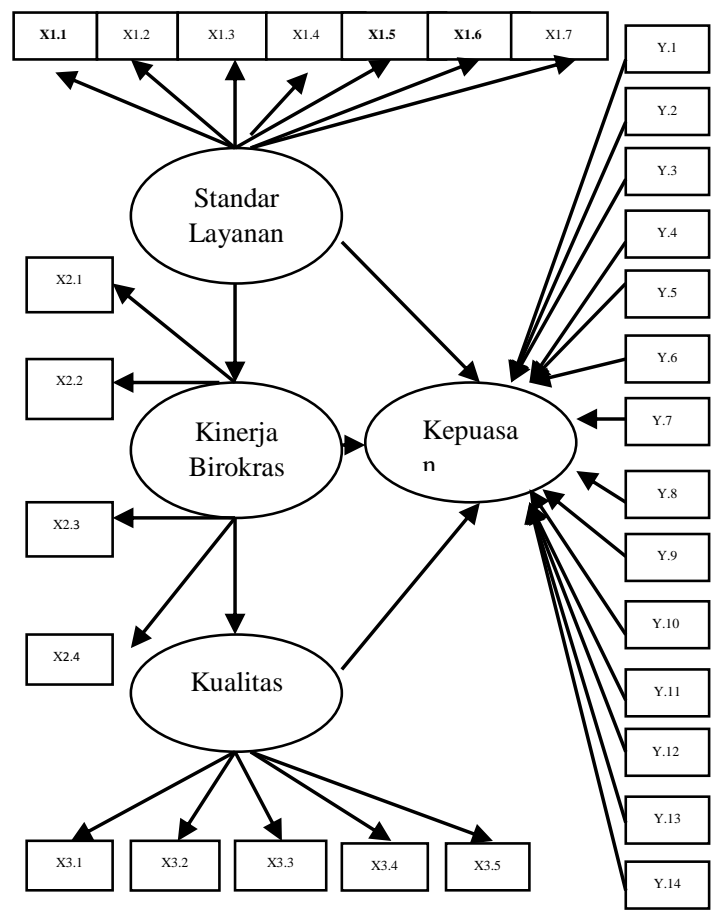

Gambar 2. Model SEM dengan Smart PLS 


\section{HASIL DAN PEMBAHASAN}

\section{Variabel Standar Layanan}

Deskripsi variabel standar layanan terdiri atas tujuh indikator yaitu prosedur pelayanan, persyaratan pelayanan, kewajaran biaya pelayanan, kepastian jadwal pelayanan, kesesuaian biaya pelayanan, keamanan lingkungan dan, kenyamanan lingkungan. Adapun capaian hasil standar layanan yang diperoleh BPPTSP dan PM Kota Denpasar berdasarkan jawaban responden melalui parameter uji yaitu dengan menggunakan ketujuh indikator tersebut dapat dilihat pada Tabel 1 .

Tabel 1. Hasil yang dicapai pada Indikator Standar Layanan di BPPTSP dan PM Kota Denpasar

\begin{tabular}{clcc}
\hline No & $\begin{array}{l}\text { Indikator } \\
\text { variabel } \\
\text { standar } \\
\text { layanan }\end{array}$ & $\begin{array}{c}\text { Rata-rata } \\
\text { Skor }\end{array}$ & Keterangan \\
\hline 1 & $\begin{array}{l}\text { Prosedur } \\
\text { pelayanan } \\
\left(\mathrm{X}_{1.1}\right)\end{array}$ & 3.55 & Baik \\
2 & $\begin{array}{l}\text { Waktu } \\
\text { penyelesaian } \\
\left(\mathrm{X}_{1.2}\right)\end{array}$ & 3.71 & Baik \\
3 & $\begin{array}{l}\text { Biaya } \\
\text { pelayanan } \\
\left(\mathrm{X}_{1.3}\right)\end{array}$ & 4.48 & Sangat Baik \\
4 & $\begin{array}{l}\text { Produk } \\
\text { pelayanan } \\
\left(\mathrm{X}_{1.4}\right)\end{array}$ & 4.07 & Sangat Baik \\
5 & $\begin{array}{l}\text { Sarana } \\
\text { pelayanan } \\
\left(\mathrm{X}_{1.5}\right)\end{array}$ & 3.74 & Baik \\
6 & $\begin{array}{l}\text { Prasarana } \\
\text { pelayanan } \\
\left(\mathrm{X}_{1.6}\right) \\
\text { Kompetensi } \\
\text { petugas } \\
\text { pelayanan } \\
\left(\mathrm{X}_{1.7}\right)\end{array}$ & 3.95 & Baik \\
\hline Rata-rata & 3.46 & Baik \\
\hline & 3.45 & Baik \\
\hline
\end{tabular}

Berdasarkan hasil uji responden tersebut dapat dilihat bahwa indikator standar layanan secara berturut turut meliputi: keamanan lingkungan $\left(\mathrm{X}_{1.7}\right)$, prosedur pelayanan $\left(\mathrm{X}_{1.1}\right)$, persyaratan pelayanan $\left(\mathrm{X}_{1.2}\right)$, kepastian jadwal pelayanan $\left(\mathrm{X}_{1,5}\right)$, dan kenyamanan lingkungan $\left(\mathrm{X}_{1,6}\right)$. Kelima indikator tersebut memiliki peran penting dalam memberikan standar layanan terbaik pada pemohon ijin. Prosedur pelayanan, persyaratan pelayanan dan kepastian jadwal berfungi penting terhadap semakin meningkatnya standar layanan yang mampu ditunjukan kepada masyarakat. Guna meningkatkan standar layanan dari BPPTSP dan PM Kota Denpasar sebagai aparatur pemerintah pada bidang perijinan dan pelayanan kepada masyarakat agar mampu menghasilkan kepuasan masyarakat.

\section{Variabel Kinerja Birokrasi}

Deskrispi variabel kinerja birokrasi terdiri atas empat indikator yaitu efisiensi pelayanan, efektifitas pelayanan, keadilan pelayanan, dan daya tanggap pelayanan. Capaian hasil kinerja birokrasi berdasarkan pengembangan marameter uji dengan menggunakan keempat indikator tersebut dapat dijelaskan melalui Tabel 2.

Berdasarkan capaian hasil analisis tersebut dapat disimpulkan bahwa indikator penilaian kinerja birokrasi pelayanan meliputi: efisiensi pelayanan $\left(\mathrm{X}_{2,1}\right)$, efektifitas pelayanan $\left(\mathrm{X}_{2,2}\right)$, keadilan pelayanan $\left(\mathrm{X}_{2,3}\right)$ dan khususnya efisiensi pelayanan $\left(\mathrm{X}_{2.4}\right)$ sudah terlaksana dengan baik, namun masih perlu ditingkatkan lagi menjadi lebih baik untuk membangun kinerja birokrasi pelayanan pengurusan ijin SIUP Agribisnis pada BPPTSP dan PM Kota Denpasar agar sesuai dengan harapan masyarakat.

Tabel 2. Hasil yang dicapai pada indikator Kinerja Birokrasi di BPPTSP dan PM Kota Denpasar

\begin{tabular}{llcc}
\hline No & $\begin{array}{l}\text { Indikator } \\
\text { variabel } \\
\text { kinerja } \\
\text { birokrasi }\end{array}$ & $\begin{array}{c}\text { Rata-rata } \\
\text { Skor }\end{array}$ & Keterangan \\
\hline 1 & $\begin{array}{l}\text { Efisiensi } \\
\text { pelayanan } \\
\left(\mathrm{X}_{2.1}\right)\end{array}$ & 3.86 & Baik \\
2 & $\begin{array}{l}\text { Efektifitas } \\
\text { pelayanan } \\
\left(\mathrm{X}_{2.2}\right)\end{array}$ & 3.88 & Baik \\
3 & $\begin{array}{l}\text { Keadilan } \\
\text { pelayanan } \\
\left(\mathrm{X}_{2.3}\right)\end{array}$ & 3.94 & Baik \\
4 & $\begin{array}{l}\text { Daya } \\
\text { tanggap } \\
\text { pelayanan } \\
\left(\mathrm{X}_{2.4}\right)\end{array}$ & 4.14 & Sangat Baik \\
\hline & & \\
\hline
\end{tabular}

\section{Variabel Kualitas Pelayanan}

Deskripsi variabel kualitas pelayanan terdiri atas lima indikator yaitu reliabilitas pelayanan, daya tanggap dalam pelayanan, jaminan pelayanan, empati dalam pelayanan, dan bukti fisik atas pelayanan pada BPPTSP dan PM Kota Denpasar. Adapun capaian hasil kualitas pelayanan berdasarkan parameter uji yang dikembangkan dengan menggunakan kelima indikator tersebut menunjukan hasil analisis yang dapat dilihat melalui Tabel 3.

Melalui pengujian terhadap bukti fisik dengan didasari atas beberapa parameter uji menunjukan 
bahwa: falisitas pelayanan masih dipandang kurang memadai bagi pemohon ijin, perlu ditingkatkannya komputerisasi untuk mempermudah pencatatan pelayanan, dan peningkatan pada fasilitas komunikasi untuk memudahkan pelayanan. Melalui hasil uji responden tersebut dapat dilihat bahwa indikator kualitas pelayanan khususnya bukti fisik dalam memberikan pelayanan $\left(\mathrm{X}_{3.5}\right)$ dalam kategori baik dan masih bisa ditingkatkan lagi untuk meningkatkan kualitas pelayanan yang semakin baik karena bukti fisik sebagai wujud konkret kualitas pelayanan sangat berpengaruh terhadap kepuasan masyarakat ketika berhubungan dengan BPPTSP dan PM Kota Denpasar khususnya dalam pengurusan ijin.

Tabel 3. Hasil yang dicapai pada indikator Kualitas Pelayanan di BPPTSP dan PM Kota Denpasar

\begin{tabular}{clcc}
\hline No & $\begin{array}{l}\text { Indikator } \\
\text { variabel } \\
\text { kualitas } \\
\text { layanan }\end{array}$ & $\begin{array}{c}\text { Rata-rata } \\
\text { Skor }\end{array}$ & Keterangan \\
\hline 1 & $\begin{array}{l}\text { Reliabilitas } \\
\left(\mathrm{X}_{3.1}\right)\end{array}$ & 4.03 & Sangat Baik \\
2 & $\begin{array}{l}\text { Daya } \\
\text { Tanggap } \\
\left(\mathrm{X}_{3.2}\right)\end{array}$ & 4.06 & Sangat Baik \\
3 & $\begin{array}{l}\text { Jaminan } \\
\left(\mathrm{X}_{3.3}\right)\end{array}$ & 4.09 & Sangat Baik \\
4 & $\begin{array}{l}\text { Empati } \\
\left(\mathrm{X}_{3.4}\right)\end{array}$ & 4.29 & Sangat Baik \\
5 & $\begin{array}{l}\text { Bukti Fisik } \\
\left(\mathrm{X}_{3.5}\right)\end{array}$ & 3.77 & Baik \\
\hline & Rata-rata & 4.05 & Sangat Baik \\
\hline
\end{tabular}

\section{Variabel Kepuasan Masyarakat}

Deskripsi variabel kepuasan masyarakat berdasarkan atas indeks kepuasan masyarakat terdiri atas empat belas indikator yaitu prosedur pelayanan, persyaratan pelayanan, kejelasan petugas pelayanan, kedisiplinan petugas pelayanan, tanggung jawab petugas pelayanan, kemampuan petugas pelayanan, kecepatan pelayanan, keadilan pelayanan, kesopanan petugas pelayanan, kewajaran biaya pelayanan, kepastian biaya pelayanan, kepastian jadwal pelayanan, kenyamanan lingkungan, dan keamanan pelayanan atas pelayanan pada BPPTSP dan PM Kota Denpasar. Adapun capaian hasil kepuasan masyarakat yang mampu diraih BPPTSP dan PM Kota Denpasar berdasarkan asumsi menggunakan keempat belas indikator IKM dapat dilihat melalui Tabel 4 sebagai berikut.
Berdasarkani hasil uji responden tersebut dapat dilihat bahwa indikator kepuasan masyarakat tergolong baik, namun masih perlu ditingkatkan lagi khususnya untuk indicator keamanan $\left(\mathrm{Y}_{14}\right)$. Terutama dalam hal keamanan tempat parkir agar disediakan tukang parkir yang memantau areal parkir selama jam kerja, sehingga masyarakat yang akan berkunjung ke BPPTSP dan PM Kota Denpasar merasa lebih aman tanpa harus takut kehilangan helm ataupun kendaraan bermotor. Kemanan yang terjamin akan meningkatkan kepuasan masyarakat dalam mengurus ijin SIUP usaha Agribisnis di BPPTSP dan PM Kota Denpasar.

Tabel 4. Hasil yang dicapai pada Indikator Kepuasan Masyarakat di BPPTSP dan PM Kota Denpasar melalui indeks kepuasan masyarakat

\begin{tabular}{|c|c|c|c|}
\hline No & $\begin{array}{l}\text { Indikator } \\
\text { variabel } \\
\text { kepuasan } \\
\text { masyarakat }\end{array}$ & $\begin{array}{l}\text { Rata- } \\
\text { rata } \\
\text { skor }\end{array}$ & Keterangan \\
\hline 1 & $\begin{array}{l}\text { Prosedur } \\
\text { layanan }\left(\mathrm{Y}_{1}\right)\end{array}$ & 3.82 & Baik \\
\hline 2 & Persyaratan $\left(\mathrm{Y}_{2}\right)$ & 3.92 & Baik \\
\hline 3 & Kejelasan $\left(\mathrm{Y}_{3}\right)$ & 3.94 & Baik \\
\hline 4 & $\begin{array}{l}\text { Kedisiplinan } \\
\left(\mathrm{Y}_{4}\right)\end{array}$ & 4.16 & Sangat Baik \\
\hline 5 & $\begin{array}{l}\text { Tanggungjawab } \\
\left(\mathrm{Y}_{5}\right)\end{array}$ & 3.72 & Baik \\
\hline 6 & $\begin{array}{l}\text { Kemampuan } \\
\left(\mathrm{Y}_{6}\right)\end{array}$ & 4.09 & Sangat Baik \\
\hline 7 & $\operatorname{Kecepatan}\left(\mathrm{Y}_{7}\right)$ & 3.85 & Baik \\
\hline 8 & Keadilan $\left(\mathrm{Y}_{8}\right)$ & 3.78 & Baik \\
\hline 9 & Kesopanan $\left(\mathrm{Y}_{9}\right)$ & 3.67 & Baik \\
\hline 10 & Kewajaran $\left(\mathrm{Y}_{10}\right)$ & 4.14 & Sangat Baik \\
\hline 11 & $\begin{array}{l}\text { Kepastian biaya } \\
\left(\mathrm{Y}_{11}\right)\end{array}$ & 3.72 & Baik \\
\hline 12 & $\begin{array}{l}\text { Kepastian jadwal } \\
\left(\mathrm{Y}_{12}\right)\end{array}$ & 3.51 & Baik \\
\hline 13 & $\begin{array}{l}\text { Kenyamanan } \\
\left(\mathrm{Y}_{13}\right)\end{array}$ & 3.98 & Sangat Baik \\
\hline 14 & Keamanan $\left(\mathrm{Y}_{14}\right)$ & 3.44 & Baik \\
\hline & Rata-rata & 3.84 & Baik \\
\hline
\end{tabular}

\section{Hasil Pengujian Hipotesis}

Pengujian hipotesis dilakukan melalui evaluasi koefisien jalur struktural yang bertujuan untuk menganalisis standar layanan, kinerja birokrasi dan kualitas pelayanan terhadap kepuasan masyarakat. Berdasarkan hasil yang diperoleh, maka dibutuhkan analisis terhadap hasil pengujian model untuk mengetahui koefisien masing-masing jalur. Pengujian koefisien jalur struktural dilakukan untuk menjawab hipotesis penelitian dan juga untuk mengetahui besarnya pengaruh masing-masing variabel. Hasil pengujian model dan hipotesis dapat dilihat pada Tabel 5 . 
Berdasarkan hasil pengujian hipotesis maka dapat disimpulkan bahwa seluruh variable memiliki hubungan yang positif dan sangat signifikan. Hal ini membuktikan bahwa seluruh variabel sangat mempengaruhi dengan kepuasan masyarakat dalam mengurus ijin usaha perdagangan Agribisnis di BPPTSP dan PM kota Denpasar.

Tabel 5. Koefisien Jalur Struktural

\begin{tabular}{lccl}
\hline \multicolumn{1}{c}{$\begin{array}{c}\text { Hubungan Antar } \\
\text { Variabel }\end{array}$} & $\begin{array}{c}\text { Entire } \\
\text { sample } \\
\text { estimate }\end{array}$ & $\begin{array}{c}\text { T- } \\
\text { Statistic }\end{array}$ & Keterangan \\
\hline $\begin{array}{l}\text { Kinerja } \\
\text { Birokrasi-> } \\
\text { Kepuasan } \\
\text { Masyarakat }\end{array}$ & 0.188 & 2.734 & $\begin{array}{l}\text { Positif dan } \\
\text { Sangat } \\
\text { Signifikan }\end{array}$ \\
$\begin{array}{l}\text { Kinerja } \\
\text { Birokrasi-> } \\
\text { Kualitas } \\
\text { Pelayanan }\end{array}$ & 0.498 & 4.575 & $\begin{array}{l}\text { Positif dan } \\
\text { Sangat } \\
\text { Signifikan }\end{array}$ \\
$\begin{array}{l}\text { Kualitas } \\
\text { Pelayanan-> } \\
\text { kepuasan }\end{array}$ & & & \\
Masyarakat & 0.970 & 2.931 & $\begin{array}{l}\text { Positif dan } \\
\text { Sangat }\end{array}$ \\
Standar & & & Signifikan \\
$\begin{array}{l}\text { Layanan-> } \\
\text { Kepuasan } \\
\text { Masyarakat }\end{array}$ & 0.666 & 3.003 & $\begin{array}{l}\text { Positif dan } \\
\text { Sangat } \\
\text { Signifikan }\end{array}$ \\
$\begin{array}{l}\text { Standar } \\
\text { Layanan- } \\
>\text { Kinerja } \\
\text { Birokrasi }\end{array}$ & & & Positif dan \\
\hline
\end{tabular}

\section{SIMPULAN DAN SARAN}

\section{Simpulan}

Berdasarkan penelitian dan hasil analisis yang telah dilakukan dapat disimpulkan berbagai simpulan yaitu sebagai berikut.

1) Apabila standar layanan yang saat ini telah digunakan mampu ditingkatkan maka kepuasan masyarakat dalam hal ini adalah pemohon ijin langsung akan meningkat.

2) Kinerja birokrasi pelayanan yang saat ini diterapkan sebagai alur pengajuan perijinan dipandang sudah baik, namun masih perlu ditingkatkan untuk penyempurnaan system pelayanan perijinan.

3) Kualitas pelayanan sebagai bentuk yang dapat diamati, dirasakan dan dinilai secara langsung oleh masyarakat selaku pemohon ijin sudah baik, namun perlu ditingkatkan lagi untuk memberikan pelayanan yang maksimal kepada masyarakat.

4) Standar pelayanan pada BPPTSP dan PM Kota Denpasar memiliki pengaruh yang besar terhadap kinerja birokrasi pelayanan.
5) Semakin meningkatnya kinerja birokrasi pelayanan yang mampu diwujudkan BPPTSP dan PM Kota Denpasar akan meningkatkan kualitas pelayanan yang mampu diberikan pada masyarakat..

\section{Saran}

Berdasarkan penelitian dan hasil analisis tersebut, akan direkomendasikan beberapa saran yaitu.

1) Berdasarkan penelitian yang telah dilakukan masih ada masyarakat yang kekurangan waktu dalam mengurus ijin usaha. Melihat kondisi tersebut, maka perlu diterapkan sistem baru terkait dengan pelayanan pengurusan ijin untuk standar layanan yang lebih efektif, efisien dan inovatif melalui sistem pelayanan online.

2) Peningkatan kinerja birokrasi pelayanan yang diperlukan pihak pemohon ijin adalah berupa kecepatan daya tanggap pihak BPPTSP dan PM Kota Denpasar dalam menanggapi berbagai macam pertanyaan ataupun keluhan terkait dengan pelayanan perijinan di Kota Denpasar. Penyediaan sarana tempat photo copy di areal pengurusan ijin juga sangat diperlukan untuk mempermudah pihak pemohon ijin agar tidak perlu keluar gedung hanya untuk photo copy selembar berkas yang kurang.

3) BPPTSP dan PM Kota Denpasar perlu meningkatkan kualitas pelayanan yang menjadi pandangan awal dari masyarakat ketika mengurus ijin usaha di Kota Denpasar. Pemberian pelatihan kepribadian, etika kesopanan (manner) dan penampilan (grooming) terhadap karyawan BPPTSP dan PM Kota Denpasar akan menambah kualitas kerja karyawan dalam melayani masyarakat.

\section{UCAPAN TERIMA KASIH}

Melalui e-jurnal ini saya mengucapkan terima kasih kepada pihak BPPTSP dan PM Kota Denpasar yang sudah bersedia memberikan kelengkapan data untuk penelitian ini, sehingga e-jurnal ini dapat diselesaikan dengan baik.

\section{DAFTAR PUSTAKA}

Keputusan Menteri Pendayagunaan Aparatur Negara Nomor KEP/25/M/PAN/2/2004 tentang Pedoman Penyusunan Indeks Kepuasan Masyarakat Unit Pelayanan Instansi Pemerintah.

Kotler, 2001, Prinsip-prinsip Pemasaran, Jilid 2, Edisi Kedelapan, Jakarta, Erlangga

Rachmadi. 2008. "Pengaruh Kualitas Pelayanan terhadap Kepuasan Pasien Rawat Inap Kelas III di RSUD Kabupaten Karimun". Tesis, Universitas Terbuka. 
Sinambela, dan Lijan Poltak. 2007. Reformasi Pelayanan Publik: Teori, Kebijakan, dan Implementasi. Jakarta: Bumi Aksara.

Wahyuni, 2006, Metodologi Penelitian dan Bisnis, Penerbit Andi, Yogyakarta..

Musgrave, Richard A dan Peggy B. Musgrave. 1980. Public Finance in Theory and Practice. Edisi ketiga. Tokyo : McGraw Hill International Book Company.

Thoha, Miftah. 2005. Perilaku Organisasi : Konsep Dasar dan Aplikasinya. Jakarta : Raja Grafindo Persada.

Tjiptono, F. 2001. Service Management Mewujudkan Layanan Prima.Yogyakarta: Andi.

2007. Strategi Pemasaran. Edisi Pertama. Yogyakarta: Andi Offset. 
Vivi Febryana, et. al., Analisis Kepuasan....|27 